University of Nebraska - Lincoln

DigitalCommons@University of Nebraska - Lincoln

\title{
A Putative Quantitative Trait Locus on Chromosome 20 Associated with Bovine Pathogenic Disease Incidence
}

E. Casas

US Meat Animal Research Center, USDA, ARS, Clay Center, NE

G. Snowder

US Meat Animal Research Center, USDA, ARS, Clay Center, NE

Follow this and additional works at: https://digitalcommons.unl.edu/usdaarsfacpub

Part of the Agricultural Science Commons

Casas, E. and Snowder, G., "A Putative Quantitative Trait Locus on Chromosome 20 Associated with Bovine Pathogenic Disease Incidence" (2008). Publications from USDA-ARS / UNL Faculty. 237. https://digitalcommons.unl.edu/usdaarsfacpub/237

This Article is brought to you for free and open access by the U.S. Department of Agriculture: Agricultural Research Service, Lincoln, Nebraska at DigitalCommons@University of Nebraska - Lincoln. It has been accepted for inclusion in Publications from USDA-ARS / UNL Faculty by an authorized administrator of DigitalCommons@University of Nebraska - Lincoln. 


\title{
A putative quantitative trait locus on chromosome 20 associated with bovine pathogenic disease incidence ${ }^{1,2}$
}

\author{
E. Casas ${ }^{3}$ and G. D. Snowder
}

US Meat Animal Research Center, USDA, ARS, Clay Center, NE 68933

\begin{abstract}
The objective of this study was to detect QTL associated with the incidence of multiple pathogenic diseases in offspring from half-sib bovine families. Four $\mathrm{F}_{1}$ sires were used to produce offspring: Brahman $\times$ Hereford $(\mathrm{BH} ; \mathrm{n}=547)$, Piedmontese $\times$ Angus $(\mathrm{PA} ; \mathrm{n}$ $=209)$, Brahman $\times$ Angus $(n=176)$, and Belgian Blue $\times$ MARC III $(\mathrm{n}=246)$. Treatment records for bovine respiratory disease, infectious keratoconjunctivitis (pinkeye), and infectious pododermatitis (footrot) were available for all of the offspring from birth to slaughter. The incidences of these 3 microbial pathogenic diseases were combined into a single binary trait to represent an overall pathogenic disease incidence. Offspring diagnosed and treated for 1 or more of the previously mentioned pathogenic diseases were coded as a 1 for affected. Cattle with no treatment record were coded
\end{abstract}

as 0 for healthy. A putative QTL for pathogenic disease incidence was detected in the family derived from the $\mathrm{BH}$ sire at the genome-wise suggestive level. This was supported by evidence, in the same chromosomal region, of a similar QTL in the family derived from the PA sire. The maximum $F$-statistic $(F=13.52 ; P=0.0003)$ was located at cM 18. The support interval of the QTL spanned from cM 9 to 28. Further studies should explore this QTL by using other bovine populations to further confirm the QTL and refine the QTL support interval. Offspring inheriting the Hereford allele, in the family from the $\mathrm{BH}$ sire, and the Angus allele, in the family from the PA sire, were less susceptible to incidence of pathogenic diseases, when compared with those inheriting the Brahman allele and Piedmontese allele, from the $\mathrm{BH}$ and $\mathrm{PA}$ sires, respectively.

Key words: cattle, disease, pathogen, quantitative trait locus

(C)2008 American Society of Animal Science. All rights reserved.

J. Anim. Sci. 2008. 86:2455-2460

doi:10.2527/jas.2008-0933

\section{INTRODUCTION}

The economic cost of pathogenic diseases is one of the most significant factors affecting the profitability of cow-calf producers and feedlot operators. The most prevalent pathogenic diseases affecting feedlot cattle include bovine respiratory disease, infectious keratoconjunctivitis (pinkeye), and infectious pododermatitis (footrot). These diseases are caused by a variety of microbial pathogens. Pathogens associated with bovine respiratory disease include viruses (i.e., bovine viral diarrhea and parainfluenza 3), bacteria (i.e., Mannheimia hemolitica), and mycoplasma (Snowder et al., 2006). The bacteria Moraxella bovis is the most com-

\footnotetext{
${ }^{1}$ Mention of a trade name, proprietary product, or specified equipment does not constitute a guarantee or warranty by the USDA and does not imply approval to the exclusion of other products that may be suitable.

${ }^{2}$ The authors thank S. Nejezchleb and D. Brinkerhoff for technical assistance and J. Watts for secretarial support. Our appreciation to G. Hays and the cattle crew for outstanding husbandry.

${ }^{3}$ Corresponding author: eduardo.casas@ars.usda.gov

Received February 6, 2008.

Accepted May 19, 2008.
}

mon pathogen associated with infectious keratoconjunctivitis (Brown et al., 1998). Fusobacterium necrophorum and Porphyromonas spp. have been considered the main bacterial pathogens associated with infectious pododermatitis (Checkley et al., 2005).

Because cattle are exposed to a diversity of microbial pathogens, genetic selection to reduce disease incidence may consider the possibility of selecting for an enhanced resistance to a multiplicity of pathogens. Additive genetic effects are known to influence resistance to specific diseases such as pinkeye (Snowder et al., 2005) and respiratory disease (Snowder et al., 2006) in beef cattle. In addition, a putative QTL associated with pinkeye has been reported (Casas and Stone, 2006). However, QTL associated with resistance to multiple pathogenic diseases have not been reported. Therefore, the objective was to detect QTL associated with combined incidences of 3 pathogenic diseases in half-sib families.

\section{MATERIALS AND METHODS}

Experimental procedures were approved and performed in accordance with US Meat Animal Research 
Center Animal Care Guidelines and the Guide for Care and Use of Agricultural Animals in Agricultural Research and Teaching (FASS, 1999).

\section{Animals}

Four half-sib families were developed at the US Meat Animal Research Center to detect QTL affecting economically important traits in beef cattle, and were described previously (Keele et al., 1999; Casas et al., $2000,2003,2004)$. One family was developed by using a Brahman $\times$ Hereford $(\mathbf{B H})$ sire mated to Hereford, Angus, and $\mathrm{F}_{1}$ cows from the Germplasm Evaluation Project Cycle IV to produce 288 offspring in 1994. In 1996, the BH sire was mated to MARCIII (one-fourth Hereford, one-fourth Angus, one-fourth Red Poll, and one-fourth Pinzgauer) cows to produce 259 offspring (547 total progeny from the $\mathrm{BH}$ sire). The $\mathrm{F}_{1}$ cows were the offspring of Hereford, Angus, Shorthorn, Charolais, Gelbvieh, Pinzgauer, Galloway, Longhorn, Nellore, Piedmontese, or Salers bulls mated to Hereford and Angus cows. Calves of the BH sire were weaned at an average age of $187 \mathrm{~d}$ and slaughtered at an average age of $467 \mathrm{~d}$.

The second half-sib family was developed by using a Brahman $\times$ Angus (BA) sire mated to Hereford, Angus, MARCIII, and $\mathrm{F}_{1}$ cows from the Germplasm Evaluation Project Cycle IV to produce 88 offspring in 1995, and mated to MARCIII cows in 1996 to produce 88 offspring (176 total progeny from the BA sire). Breed of sires and dams for the $\mathrm{F}_{1}$ cows were similar to those previously mentioned. Calves were weaned at an average age of $205 \mathrm{~d}$ and slaughtered at an average age of $455 \mathrm{~d}$.

The other 2 half-sib families were produced in 1995 from a Piedmontese $\times$ Angus (PA), and a Belgian Blue $\times$ MARCIII (BM) sire, mated primarily to MARCIII cows. A total of 246 and 209 offspring were produced by each PA and BM sire, respectively. Calves were weaned at an average age of $200 \mathrm{~d}$. Both sires, PA and $\mathrm{BM}$, were heterozygous for the myostatin gene, which produces the double-muscling condition in cattle. Approximately one-half of the offspring inherited 1 copy of the allele that produces double muscling, and the other half did not.

\section{Trait Analyzed}

Disease incidence was observed from birth to slaughter. Calves were monitored daily by the staff veterinarian, the beef cattle research technicians, or both. When observed with clinical symptoms, calves were administered an appropriate treatment. Respiratory disease was treated by administering 1 or more medications (oxytetracycline, ceftiofur, flunixin meglumine, florfenicol, tylosin, enrofloxacin, and sulfadimethoxine) as described by Snowder et al. (2006). Treatment of infectious keratoconjunctivitis included injections with antibiotics (oxytetracycline and ceftiofur sodium) and
Table 1. Number of animals treated for respiratory disease (BRD), infectious keratoconjunctivitis (IBK), and infectious pododermatitis (IP), total disease incidences, and total animals by family ${ }^{1}$

\begin{tabular}{lrrrr}
\hline \hline Condition & BH & BA & BM & PA \\
\hline BRD & 49 & 12 & 1 & 2 \\
IBK & 36 & 0 & 15 & 7 \\
IP & 22 & 2 & 0 & 5 \\
Incidence $^{2}$ & 96 & 14 & 16 & 14 \\
Family size $^{2}$ & 547 & 176 & 246 & 209 \\
\hline
\end{tabular}

${ }^{1}$ Families derived from $\mathrm{F}_{1}$ sires: $\mathrm{BH}=$ Brahman $\times$ Hereford; $\mathrm{BA}=$ Brahman $\times$ Angus; $\mathrm{BM}=$ Belgian Blue $\times$ MARCIII; PA $=$ Piedmontese $\times$ Angus.

${ }^{2}$ Total incidence may be less than the sum of disease conditions, because some animals were treated for more than one disease.

topical application of cloxacillin benzathine to the eye and covering with an eye patch (Snowder et al., 2005). Infectious pododermatitis was treated by administering oxytetracycline, ceftiofur, and sulfadimethoxine. Data recorded at treatment included field diagnosis, treatment protocol, date, and calf identity.

For analyses, calves treated for respiratory disease, infectious keratoconjunctivitis (pinkeye), or infectious pododermatitis (footrot) were classified as affected by a microbial pathogenic disease and coded as " $1 . "$ No distinction was made regarding whether the animal was treated multiple times for the same disease or different diseases. Animals not receiving any treatment were classified as unaffected and coded as "0." Affected calves were assumed to be less genetically resistant to the causative pathogens of the 3 diseases. Therefore, the trait was defined as incidence of treatment for 1 or more of 3 pathogenic diseases. Table 1 shows the number of animals diagnosed and treated for bovine respiratory disease, infectious keratoconjunctivitis, or infectious pododermatitis, the total number of animals included in the "incidence" trait, and the total number of animals included by family.

\section{Genomic Screening}

The microsatellite markers used in the genomic screening for each family were described previously in detail by Casas et al. (2000, 2003, 2004). The screening design was to cover $2,850 \mathrm{cM}$ of the genome, with markers spanning the genome approximately every 20 cM. Informative markers were chosen within a family based on their location in each chromosome and ease of scoring. Amplification reactions for each marker were made with purified DNA extracted from blood with a saturated salt procedure (Miller et al., 1988). Amplification conditions have been described elsewhere (Kappes et al., 1997).

\section{Statistical Analysis}

Analysis of the 4 half-sib families has been described previously (Casas et al., 2001, 2004; Casas and Stone, 
2006). An $F$-statistic profile was generated at 1 -cM intervals for each chromosome by regression of the phenotype on the conditional probability of receiving the paternal grandsire allele. This allele was inherited from the Brahman for the $\mathrm{BH}$ and $\mathrm{BA}$ sires, from the Belgian Blue for the BM sire, and from the Piedmontese for the PA sire. Data were analyzed by using a regression analysis for half-sib populations (Haley et al., 1994). For the half-sib family from the BH sire, the model included the fixed effects of sex (steer or heifer), year of birth (1994 or 1996), and dam line within year of birth. A similar model was used for the half-sib family from the BA sire, but with different years of birth (1995 or 1996). The models used for the half-sib families from the BM and PA sires included only the effects of dam line and sex, and the conditional probability of inheriting the myostatin allele that produces double muscling. The conditional probability of inheriting the paternal grandsire allele was included in all models. This last conditional probability was calculated with a FORTRAN program (Casas et al., 2000). Analysis for each chromosome was generated by using the GLM procedure (SAS Inst. Inc., Cary, NC). The 1-LOD dropoff method was used to calculate the support interval for the putative QTL suggestive of linkage (Ott, 1992).

Thresholds were calculated according to Lander and Kruglyak (1995). An $F$-statistic was considered genome-wise suggestive of linkage if it exceeded a value of $F=10.0$, which is equivalent to 1 expected false positive per genomic scan. The $F$-statistic was considered significant at the chromosome-wise level of $P=0.01$ if it exceeded a value of $F=8.5$, and of $P=0.05$ level if it exceeded an $F=5.0$. Significance at the chromosomewise level was considered only for inference purposes.

\section{RESULTS}

One region on bovine chromosome 20 showed evidence of the existence of a putative QTL for pathogenic disease incidence (Figure 1). Markers used in each family, and their relative positions within the linkage group, are shown in Table 2. The putative QTL for pathogenic disease incidence was detected in the halfsib family derived from the $\mathrm{BH}$ sire at the genome-wise suggestive level or was highly significant $(P=0.01)$ at the chromosome-wise level. The putative QTL was further supported by additional evidence found in the family derived from the PA sire, of a similar QTL in the same chromosomal region, which was significant at the chromosomal-wise $(P=0.05)$ level. There was no evidence $(P=0.51)$ of a putative QTL for pathogenic disease incidence in the family derived from the BM sire. The support interval of the QTL within the BHsired family spanned from cM 9 to 28 .

Table 3 summarizes the location, significance, and magnitude of the QTL for pathogenic disease incidence in $\mathrm{BH}$ - and PA-sired families. Animals inheriting the Brahman allele, in the family from the $\mathrm{BH}$ sire, had a
$12 \%$ greater prevalence of pathogenic disease incidence when compared with those inheriting the Hereford allele. At this chromosomal region, $23.5 \%$ of the family members that inherited the Brahman allele were diagnosed with a pathogenic disease incidence, compared with $11.5 \%$ of the family members that inherited the Hereford allele diagnosed with a pathogenic disease incidence. There also was evidence supporting the presence of this QTL in the family from the PA family. In this family, animals inheriting the Piedmontese allele from the sire had a $10 \%$ greater prevalence of pathogenic disease incidence when compared with those inheriting the Angus allele. The incidence of diagnosed pathogenic diseases among animals inheriting the Piedmontese allele was $11.7 \%$, compared with $1.7 \%$ of those inheriting the Angus allele.

\section{DISCUSSION}

The hypothesis of this study was that incidence of pathogenic diseases has a similar immune response from the host. Animals rely on the major histocompatibility complex to provide immunity against infectious diseases (Zekarias et al., 2002). However, little is known about the regulatory mechanisms of this complex. It is likely that similar pathways may regulate immune response, regardless of the pathogen. To assess the validity of this hypothesis, records from 3 of the most important diseases in cattle were combined to generate a single trait representing an overall incidence of pathogenic diseases.

The objective was to ascertain whether specific chromosomal regions were associated with a variety of pathogenic infections in cattle. Evidence was found indicating the centromeric region of bovine chromosome 20 harbors a putative QTL related to the combined incidence of the 3 pathogenic diseases considered. Two of the 4 independent half-sib families (BH and PA) studied provided support for the presence of the putative QTL. A third family (BA), the family with the fewest animals, also showed a tendency toward the presence of a putative QTL for pathogenic disease incidence. These independent and supportive results suggest the presence of a gene, or group of genes, on this region of bovine chromosome 20 involved in the incidence of pathogenic diseases in cattle.

It is doubtful that a single disease, such as infectious keratoconjunctivitis, biased the identification of the QTL for incidence of pathogenic disease. Information derived from the $\mathrm{BH}$-sired family was previously used to identify putative QTL associated with infectious bovine keratoconjunctivitis (Casas and Stone, 2006). This information was used in the present study. Because inclusion of additional diseases with infectious bovine keratoconjunctivitis in the present study increased the significance of the QTL previously reported for infectious bovine keratoconjunctivitis, the incidence of this trait could not have been a limiting factor in the detec- 
tion of this QTL. In addition, the presence of the QTL associated with incidence of pathogenic diseases was supported with information from additional families. When bovine respiratory disease, infectious keratoconjunctivitis, and pododermatitis were analyzed individually, the only putative QTL detected in this chromosome was observed in the family derived from the $\mathrm{BH}$ sire.

Immunological defense mechanisms are highly complex and not limited to a single genomic region. A plethora of QTL on different chromosomes have been detected and associated with somatic cell score and mastitis in dairy cattle (Rodriguez-Zas et al., 2002; Ashwell et al., 2004; Ron et al., 2004). Gasparin et al. (2007), using an $\mathrm{F}_{2}$ population of cattle derived from Bos taurus and Bos indicus, identified putative QTL for ectoparasite resistance on chromosomes 5, 7, and 14 .

In the scientific literature, there is support for QTL related to general pathogenic disease resistance within the region on chromosome 20 identified in this study. Gonda et al. (2007) identified a QTL associated with susceptibility to Johne's disease on the centromeric end of chromosome 20 in Holstein dairy cattle. They indicated that the confidence interval for the QTL spans from cM 0 to 24 . However, the study by Gonda et al. (2007) was limited to the first $24 \mathrm{cM}$ of the chromosome. Therefore, it is likely that the confidence interval reported by Gonda et al. (2007) overlaps the
Table 2. Genomic markers and their relative position used in each family ${ }^{1}$ to detect a putative QTL for incidence of multiple bovine pathogenic diseases on chromosome 20

\begin{tabular}{lccccc}
\hline \hline Marker & $\begin{array}{c}\text { Relative } \\
\text { position, cM }\end{array}$ & BH & BA & BM & PA \\
\hline BM3517 & 0.0 & X & & & \\
HEL12 & 0.7 & X & X & X & X \\
BMS1282 & 19.1 & X & X & & \\
TGLA304 & 20.0 & X & & & \\
BMS1754 & 24.4 & & & X & X \\
ILSTS068 & 29.3 & X & X & & \\
BMS1128 & 33.9 & X & X & & \\
BMS2361 & 45.0 & X & & & \\
BM4107 & 52.4 & X & X & & \\
BM703 & 54.9 & & & X & X \\
BM5004 & 64.0 & X & & & \\
BMS1719 & 64.8 & X & X & & \\
BMS521 & 75.0 & X & X & X & X \\
\hline
\end{tabular}

${ }^{1}$ Families derived from $\mathrm{F}_{1}$ sires: $\mathrm{BH}=$ Brahman $\times$ Hereford; $\mathrm{BA}=$ Brahman $\times$ Angus; $\mathrm{BM}=$ Belgian Blue $\times$ MARCIII; PA $=$ Piedmontese $\times$ Angus.

support interval of the present study. Casas and Stone (2006), analyzing the information of the half-sib family sired by $\mathrm{BH}$ used in the present study, identified a QTL associated with the probability of contracting infectious bovine keratoconjunctivitis in a region simi-

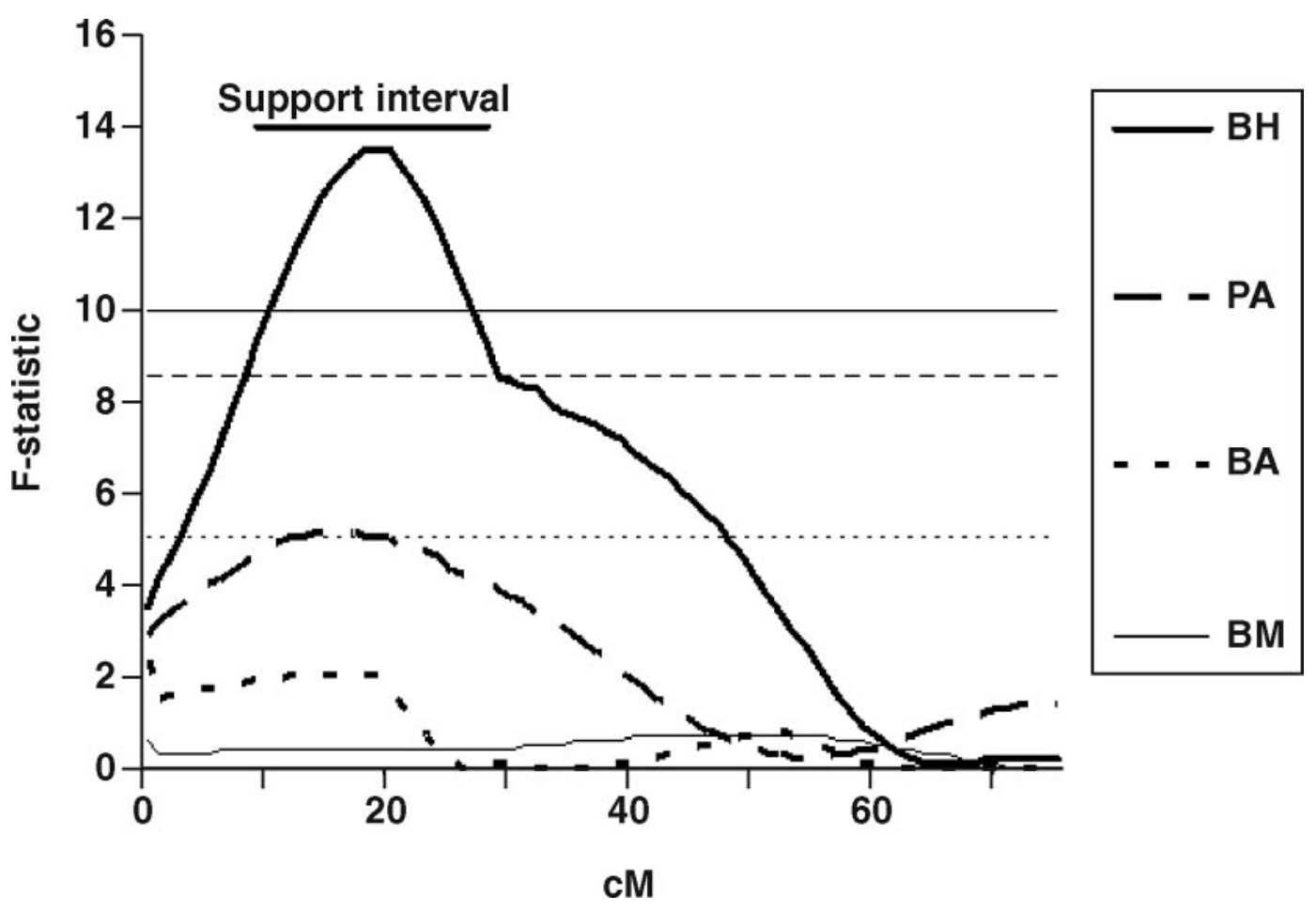

Figure 1. $F$-statistic profile and support interval for bovine pathogenic disease incidence in families derived from a Brahman $\times$ Hereford sire $(\mathrm{BH})$, a Brahman $\times$ Angus sire (BA), Belgian Blue $\times$ MARCIII sire $(\mathrm{BM})$, and a Piedmontese $\times$ Angus sire (PA), on chromosome 20. The upper horizontal line represents the genome-wide suggestive threshold $(F=10.0)$, and the middle and lower horizontal lines represent the chromosome-wide significant $(P$ $=0.01$ and 0.05 , respectively) threshold ( $F=8.5$ and 5.0, respectively). 
lar to the one in the present study. Quantitative trait loci for somatic cell score have been detected on bovine chromosome 20 (Rodriguez-Zas et al., 2002; Ashwell et al., 2004; Ron et al., 2004). Rodriguez-Zas et al. (2002) detected a QTL for somatic cell score on the centromeric region of chromosome 20. Ashwell et al. (2004) identified a QTL for somatic cell score between markers RM310 and TGLA126. Both markers are within the support interval of the present study. Ron et al. (2004) indicated that marker BM1225 was associated with somatic cell score in Israeli Holsteins. Marker BM1225 also resides within the support interval of the present study. The literature supports the presence of a QTL associated with incidence of pathogenic disease on the region of chromosome 20, where the QTL of the current study resides.

Comparative maps indicate orthology between this region of bovine chromosome 20 and human chromosome 5 (Everts-van der Wind et al., 2004). Within this region, a potential candidate gene has been identified. The Ankyrin-repeat protein 2 (ANKRA2) lies between markers BMS1282 and TGLA304 (W. Snelling, US Meat Animal Research Center, Clay Center, NE, personal communication). This gene may play a major role in the regulation of the major histocompatibility complex class II (MHC-II) genes (Krawczyk et al., 2005; McKinsey et al., 2006). The MHC-II is responsible for the immunological response in livestock. The ANKRA2 gene is 96\% paralogous to RFX-B (Long and Boss, 2005). Mutations in the RFX-B gene cause immunodeficiency by producing the bare lymphocyte syndrome (Masternak et al., 1998). Krawczyk et al. (2005) indicated that increasing the expression of ANKRA2 activates MHC-II expression, demonstrating that both genes (ANKRA2 and RFX-B) have a similar capacity to activate transcription of the MHC-II genes. Further studies need to be conducted to ascertain whether ANKRA2 is associated with the incidence of multiple pathogenic diseases in cattle.

Segregation of an allele(s) at the putative QTL may have been influenced by indirect selection for adaptation related to pathogenic diseases. Animals inheriting the Hereford and Angus allele from the sire, in the $\mathrm{BH}, \mathrm{BA}$, and PA half-sib families with evidence for the QTL, were less likely to be affected by a pathogenic disease than those inheriting the Brahman and Piedmontese allele. The Hereford and Angus breeds have been exposed to climates, management systems, and pathogens found in the United States for more than $100 \mathrm{yr}$, and for more than $40 \mathrm{yr}$ at the US Meat Animal Research Center, whereas the Brahman and Piedmontese breeds are relatively newly introduced breeds to the United States. Brahman is a tropically adapted breed, unaccustomed to the temperate climate production systems found in Nebraska. Piedmontese is a continental breed generally not as intensively managed as at the US Meat Animal Research Center. It is plausible that Hereford and Angus animals are more inherently adapted to production systems, climates, or the patho-
Table 3. Relative position, significance, and effect of the putative QTL detected for incidence of multiple bovine pathogenic diseases on chromosome 20

\begin{tabular}{lcc}
\hline \hline & \multicolumn{2}{c}{ Family $^{1}$} \\
\cline { 2 - 3 } Item & $\mathrm{BH}$ & $\mathrm{PA}$ \\
\hline Relative position, $^{2} \mathrm{cM}$ & 19 & 15 \\
$F^{3}$ & 13.52 & 5.12 \\
$P_{\text {nominal }}{ }^{3}$ & 0.0003 & 0.025 \\
$P_{\text {chromosomal }}{ }^{3}$ & 0.001 & 0.047 \\
$P_{\text {genome-wide }}$ & 0.24 & 7.49 \\
Effect $^{7}$ & $12 \pm 3 \%$ & $10 \pm 4 \%$ \\
\hline
\end{tabular}

${ }^{1}$ Families derived from $\mathrm{F}_{1}$ sires: $\mathrm{BH}=$ Brahman $\times$ Hereford; $\mathrm{PA}=$ Piedmontese $\times$ Angus.

${ }^{2}$ Relative position of the maximum $F$-statistic in centimorgans from the beginning of the linkage group according to Kappes et al. (1997).

${ }^{3}$ Maximum $F$-statistic in the interval.

${ }^{4}$ Nominal probability of a false positive for a single test.

${ }^{5}$ Chromosome-wise probability.

${ }^{6}$ Genome-wise expected number of false positives per scan (Lander and Kruglyak, 1995).

${ }^{7}$ Animals inheriting the Brahman (in family $\mathrm{BH}$ ) and Piedmontese (in family PA) allele from the sire, and that were treated for the condition, had a 12 and $10 \%$, respectively, greater prevalence of being treated for a pathogenic disease.

genic diseases in the United States when compared with Brahman and Piedmontese.

Casas and Stone (2006) identified regions on chromosomes 1 and 20 as harboring genes associated with infectious keratoconjunctivitis and hypothesized that these chromosomal regions may also be associated with the incidence of additional pathogenic diseases. Results from the current study support their hypothesis by detecting a putative QTL related to a pathogenic disease incidence trait that included 3 diseases: bovine respiratory disease, infectious keratoconjunctivitis, and infectious pododermatitis.

Certainly, further studies are needed to develop markers associated with the incidence of multiple pathogenic diseases. Single nucleotide polymorphisms in candidate genes (i.e., ANKRA2) residing in this chromosomal region should be developed and evaluated in outbred populations. Rather than dependence on treatment records, accurate diagnosis of diseases may enhance detection of other QTL. In addition, the decision on which group of diseases caused by pathogens to include in an incidence trait may bias QTL detection.

In conclusion, this is the report of a putative QTL associated with incidence of multiple pathogenic diseases in cattle. Within the chromosomal region of the putative QTL, the presence of a candidate gene involved in the regulation of the MHC-II and reports of additional genes associated with other diseases in the same genomic region suggest that this QTL is likely to be real. Although most previously reported QTL were related to economically important production traits, we suggest a QTL related to the most costly diseases in cattle production. Health records may be useful to identify loci with general influence on the immune system. 


\section{LITERATURE CITED}

Ashwell, M. S., D. W. Heyen, T. S. Sonstegard, C. P. Van Tassell, Y. Da, P. M. VanRaden, M. Ron, J. I. Weller, and H. A. Lewin. 2004. Detection of quantitative trait loci affecting production, health and reproductive traits in Holstein cattle. J. Dairy Sci. 87:468-475.

Brown, M. H., A. L. Brightman, B. W. Fenwick, and M. A. Rider. 1998. Infectious bovine keratoconjunctivitis: A review. J. Vet. Intern. Med. 12:259-266.

Casas, E., J. W. Keele, S. D. Shackelford, M. Koohmaraie, and R. T. Stone. 2004. Identification of quantitative trait loci for growth and carcass composition in cattle. Anim. Genet. 35:2-6.

Casas, E., S. D. Shackelford, J. W. Keele, M. Koohmaraie, T. P. L. Smith, and R. T. Stone. 2003. Detection of quantitative trait loci for growth and carcass composition in cattle. J. Anim. Sci. 81:2976-2983.

Casas, E., S. D. Shackelford, J. W. Keele, R. T. Stone, S. M. Kappes, and M. Koohmaraie. 2000. Quantitative trait loci affecting growth and carcass composition of cattle segregating alternate forms of myostatin. J. Anim. Sci. 78:560-569.

Casas, E., and R. T. Stone. 2006. Putative quantitative trait loci associated with the probability of contracting infectious bovine keratoconjunctivitis. J. Anim. Sci. 84:3180-3184.

Casas, E., R. T. Stone, J. W. Keele, S. D. Shackelford, S. M. Kappes, and M. Koohmaraie. 2001. A comprehensive search for quantitative trait loci affecting growth and carcass composition of cattle segregating alternative forms of the myostatin gene. J. Anim. Sci. 79:854-860.

Checkley, S. L., E. D. Janzen, J. R. Campbell, and J. J. McKinnon. 2005. Efficacy of vaccination against Fusobacterium necrophorum infection for control of liver abscesses and footrot in feedlot cattle in western Canada. Can. Vet. J. 46:1002-1007.

Everts-van der Wind, A., S. R. Kata, M. R. Band, M. Rebeiz, D. M. Larkin, R. E. Everts, C. A. Green, L. Liu, S. Natarajan, T. Goldammer, J. H. Lee, S. McKay, J. E. Womack, and H. A. Lewin. 2004. A 1463 gene cattle-human comparative map with anchor points defined by human genome sequence coordinates. Genome Res. 14:1424-1437.

FASS. 1999. Guide for Care and Use of Agricultural Animals in Agricultural Research and Teaching. 1st ed. Fed. Anim. Sci. Soc., Savoy, IL.

Gasparin, G., M. Miyata, L. L. Coutinho, M. L. Martinez, R. L. Teodoro, J. Furlong, M. A. Machado, M. V. G. B. Silva, T. S. Sonstegard, and L. C. A. Regitano. 2007. Mapping of quantitative trait loci controlling tick [Riphicephalus (Boophilus) microplus] resistance on bovine chromosome 5, 7, and 14. Anim. Genet. 38:453-459.

Gonda, M. G., B. W. Kirkpatrick, G. E. Shook, and M. T. Collins. 2007. Identification of a QTL on BTA20 affecting susceptibility to Mycobacterium avium ssp. paratuberculosis infection in US Holsteins. Anim. Genet. 38:389-396.

Haley, C. S., S. A. Knott, and J. M. Elsen. 1994. Mapping QTL in crosses between outbred lines using least squares. Genetics 136:1195-1207.
Kappes, S. M., J. W. Keele, R. T. Stone, R. A. McGraw, T. S. Sonstegard, T. P. L. Smith, N. Lopez-Corrales, and C. W. Beattie. 1997. A second generation linkage map of the bovine genome. Genome Res. 7:235-249.

Keele, J. W., S. D. Shackelford, S. M. Kappes, M. Koohmaraie, and R. T. Stone. 1999. A region on bovine chromosome 15 influences beef longissimus tenderness in steers. J. Anim. Sci. 77:13641371.

Krawczyk, M., K. Masternak, M. Zufferey, E. Barras, and W. Reith. 2005. New functions of the major histocompatibility complex class II-specific transcription factor RFXANK revealed by a high-resolution mutagenesis study. Mol. Cell. Biol. 25:86078618.

Lander, E. S., and L. Kruglyak. 1995. Genetic dissection of complex traits: Guidelines for interpreting and reporting linkage results. Nat. Genet. 11:241-247.

Long, A. B., and J. M. Boss. 2005. Evolutionary conservation and characterization of the bare lymphocyte syndrome transcription factor RFX-B and its paralogue ANKRA2. Immunogenetics 56:788-797.

Masternak, K., E. Barras, M. Zufferey, B. Conrad, G. Corhals, R. Aebersold, J.-C. Sanchez, D. F. Hochstrasser, B. Mach, and W. Reith. 1998. A gene encoding a novel RFX-associated transactivator is mutated in the majority of MHC class II deficiency patients. Nat. Genet. 20:273-277.

McKinsey, T. A., K. Kuwahara, S. Bezprozvannaya, and E. N. Olson. 2006. Class II deacetylases confer signal responsiveness to the ankyrin-repeat proteins ANKRA2 and RFXANK. Mol. Biol. Cell 17:438-447.

Miller, S. A., D. D. Dykes, and H. F. Polesky. 1988. A simple salting out procedure for extracting DNA from human nucleated cells. Nucleic Acids Res. 16:1215.

Ott, J. 1992. Analysis of human genetic linkage. Rev. ed. Johns Hopkins Univ. Press, Baltimore, MD.

Rodriguez-Zas, S. L., B. R. Southey, D. W. Heyen, and H. A. Lewin. 2002. Interval and composite interval mapping of somatic cell score, yield, and components of milk in dairy cattle. J. Dairy Sci. 85:3081-3091.

Ron, M., E. Feldmesser, M. Golik, I. Tager-Cohen, D. Kliger, V. Reiss, R. Domochovsky, O. Alus, E. Serioussi, E. Ezra, and J. I. Weller. 2004. A complete scan of the Israeli Holstein population for quantitative trait loci by a daughter design. J. Dairy Sci. 87:476-490.

Snowder, G. D., L. D. Van Vleck, L. V. Cundiff, and G. L. Bennett. 2005. Genetic and environmental factors associated with incidence of infectious bovine keratoconjunctivitis in preweaned beef calves. J. Anim. Sci. 83:507-518.

Snowder, G. D., L. D. Van Vleck, L. V. Cundiff, and G. L. Bennett. 2006. Bovine respiratory disease in feedlot cattle: Environmental, genetic and economic factors. J. Anim. Sci. 84:1999-2007.

Zekarias, B., A. A. H. M. Ter Huurne, W. J. M. Landman, J. M. J. Rebel, J. M. A. Pol, and E. Gruys. 2002. Immunological basis of differences in disease resistance in the chicken. Vet. Res. 33:109-125. 